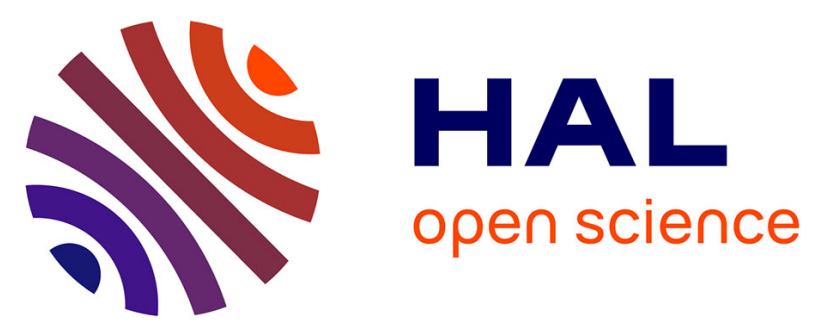

\title{
Ethynylene-analogues of hemicurcuminoids: Synthesis and ground- and excited properties of their boron difluoride complexes
}

\author{
B. Štefane, F. Požgan, E. Kim, E. Choi, J.-C. Ribierre, J.W. Wu, \\ Miguel-Armando Ponce-Vargas, Boris Le Guennic, D. Jacquemin, Gabriel \\ Canard, et al.
}

\section{To cite this version:}

B. Štefane, F. Požgan, E. Kim, E. Choi, J.-C. Ribierre, et al.. Ethynylene-analogues of hemicurcuminoids: Synthesis and ground- and excited properties of their boron difluoride complexes. Dyes and Pigments, 2017, 141, pp.38-47. 10.1016/j.dyepig.2017.02.005 . hal-01515154

HAL Id: hal-01515154

https://hal-univ-rennes1.archives-ouvertes.fr/hal-01515154

Submitted on 4 Jul 2017

HAL is a multi-disciplinary open access archive for the deposit and dissemination of scientific research documents, whether they are published or not. The documents may come from teaching and research institutions in France or abroad, or from public or private research centers.
L'archive ouverte pluridisciplinaire HAL, est destinée au dépôt et à la diffusion de documents scientifiques de niveau recherche, publiés ou non, émanant des établissements d'enseignement et de recherche français ou étrangers, des laboratoires publics ou privés. 


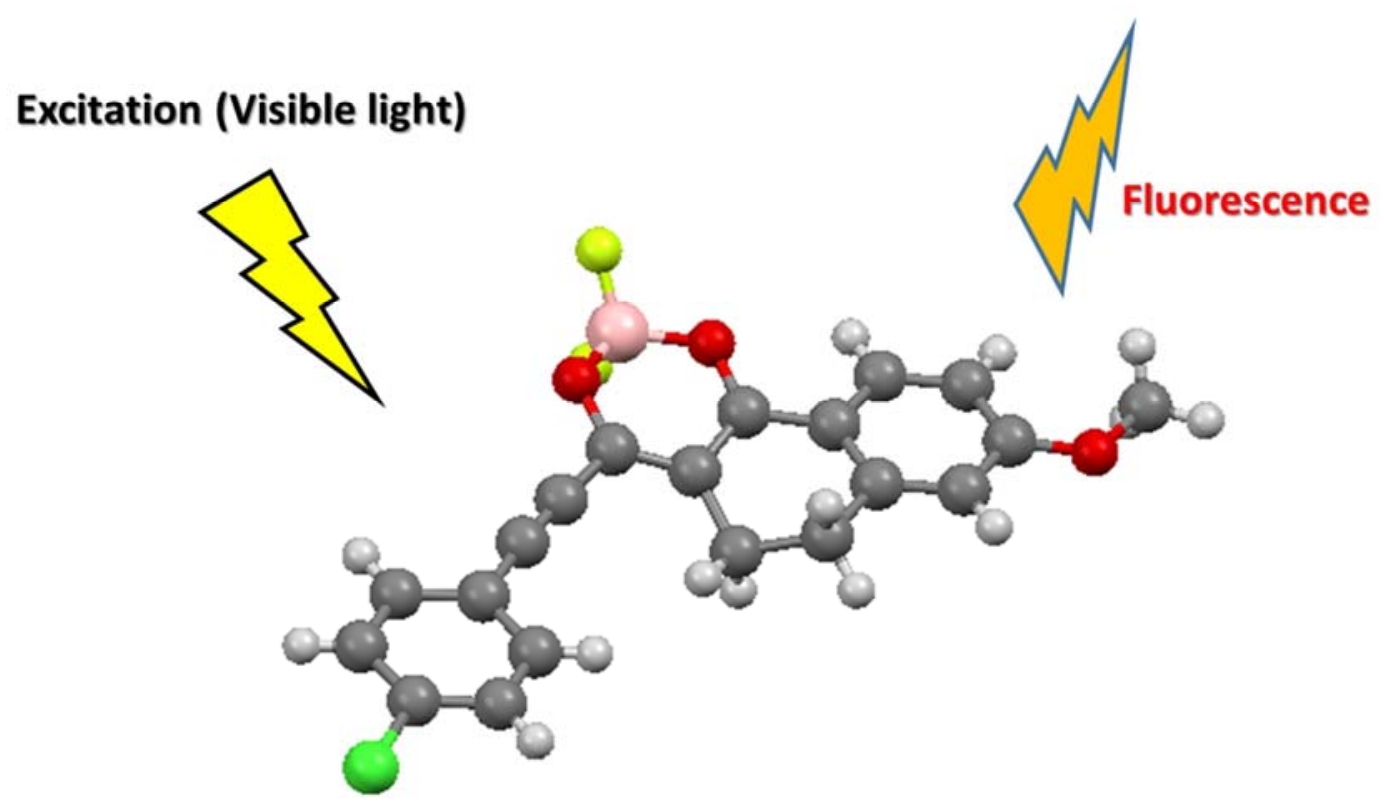




\section{Ethynylene-Analogues of Hemicurcuminoids: Synthesis and Ground- and} Excited Properties of their Boron Difluoride Complexes

Bogdan Štefane, ${ }^{\mathrm{a},{ }^{*}}$ Franc Požgan, ${ }^{\mathrm{a}}$ Eunsun Kim, ${ }^{\mathrm{b}}$ Eunyoung Choi, ${ }^{\mathrm{b}}$ Jean-Charles Ribierre, ${ }^{\mathrm{b}}$ Jeong Weon Wu, ${ }^{\mathrm{b}}$ Miguel Ponce-Vargas, ${ }^{\mathrm{c}}$ Boris Le Guennic, ${ }^{\mathrm{c},{ }^{*}}$ Denis Jacquemin, ${ }^{\mathrm{d}, \mathrm{e}}$ Gabriel Canard, ${ }^{\mathrm{f}}$ Elena Zaborova, ${ }^{\mathrm{f}}$ Frédéric Fages, ${ }^{\mathrm{f}, *}$ Anthony D’Aléo, ${ }^{\mathrm{b}, \mathrm{f},{ }^{*}}$

${ }^{\text {a }}$ Faculty of Chemistry and Chemical Technology, University of Ljubljana, Večna pot 113, SI1000 Ljubljana, Slovenia, bogdan.stefane@fkkt.uni-lj.si.

b Department of Physics, Quantum MetaMaterials Research Center, Ewha Womans University, Seoul, Korea.

${ }^{\mathrm{c}}$ Institut des Sciences Chimiques de Rennes, UMR 6226 CNRS-Université de Rennes 1, 263 Avenue du Général Leclerc, 35042 Rennes Cedex, France, boris.leguennic@univ-rennes1.fr.

d Laboratoire CEISAM, UMR CNRS 6230, Université de Nantes, 2 Rue de la Houssinière, BP 92208, 44322 Nantes Cedex 3, France.

${ }^{\mathrm{e}}$ Institut Universitaire de France, rue Descartes, 75231 Paris Cedex 05, France

${ }^{\mathrm{f}}$ Aix Marseille Univ, CNRS, CINaM UMR 7325, Campus de Luminy, Case 913, 13288 Marseille, France, frederic.fages@univ-amu.fr, daleo@cinam.univ-mrs.fr. 


\begin{abstract}
:
The synthesis, characterization and (TD)-DFT calculations of the electrochemical and photophysical properties of novel ethynylene-analogues of hemicurcuminoids are described. These dyes are both emissive in solution and in the solid state. While compounds that emit through an efficient charge transfer (CT) state show solvatochromic behavior associated with low fluorescence quantum yields, those lacking of donor groups show high fluorescence quantum yields of $70-80 \%$, in solution. The latter dyes also present the advantage to emit in the solid state in the visible region with fluorescence quantum yields up to $23 \%$. Their condensed phase spectrum can be bathochromically shifted to the near infrared region (742 $\mathrm{nm}$ ) by appending a strong donor group.
\end{abstract}

Keywords: boron difluoride complex, photophyics, fluorescence, charge transfer 


\section{Introduction}

The design and synthesis of novel fluorescent dyes with tailored properties is a constantly growing field of research due to exciting applications in bio-imaging [1-3] and emitting devices.[4-8] In those applications, the selection of the best dyes requires to optimize several parameters such as absorption and emission wavelengths, molar absorption coefficients, fluorescence quantum yields, and Stokes shifts.

Molecules containing the boron difluoride $\left(\mathrm{BF}_{2}\right)$ moiety, such as the well-known BODIPYs[9-12] and aza-BODIPYs[13-15] represent one of the most important family of fluorophores that have been exploited in many different kinds of applications, as they present very large fluorescence quantum yields in solution. However, similarly to cyanine dyes, most (aza)-BODIPY dyes show a small Stokes shift and do not exhibit luminescence in their solid state unless they feature bulky groups[16] or aggregation induced emission properties.[17, 18] In this context, we and others developed series of boron difluoride complexes of acetylacetone-like chelate,[19-27] curcuminoid[28-32] and hemicurcuminoid[33, 34] derivatives with the aim to combine the electron withdrawing $\mathrm{BF}_{2}$ moiety to electron donor groups. As such systems develop a push-pull character, this should allow overcoming the Stokes shift issue as well as the quenching of the fluorescence in the condensed phase. Indeed, $\mathrm{BF}_{2}$ complexes of curcuminoids and hemicurcuminoids proved to be versatile fluorophores allowing the preparation of fluorescent organic nanoparticles useful for bio-imaging purposes relying on both one- and two-photon excitation techniques.[31, 34, 35]
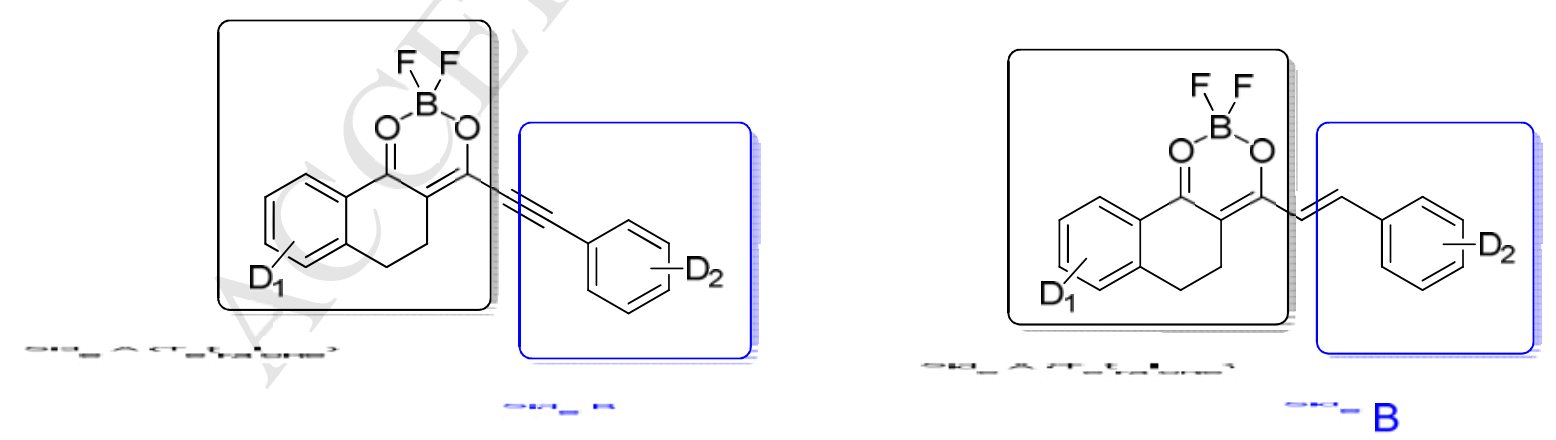

Scheme 1. Structures of the hemicurcuminoid derivatives (right) and the new ethynylene analogues (left) investigated in this study (where $\mathrm{D}_{1}$ and $\mathrm{D}_{2}$ are the donor groups). 
We report herein the synthesis and electrochemical and optical properties in both solution and solid state of an unprecedented related series of $\mathrm{BF}_{2}$-containing hemicurcuminoids in which the dioxaborine-containing subunit (side A) and the terminal aromatic group (side B) are connected via an acetylenic linkage (Scheme 1).[34] More specifically, side A consists in the $\mathrm{BF}_{2}$ complex of a tetralone-containing acetylacetone moiety and side $\mathrm{B}$ features various donor groups. We were interested in investigating the influence of the ethynylene spacer on the excited states properties in solution and fluorescence emission characteristics in the solid state and compare the properties to the corresponding vinylene compounds.[34] Density Functional Theory (DFT) and Time-Dependent Density Functional Theory (TD-DFT) calculations were performed in order to provide insights into the factors that control the optical and electrochemical properties of the hemicurcuminoid-related dyes.

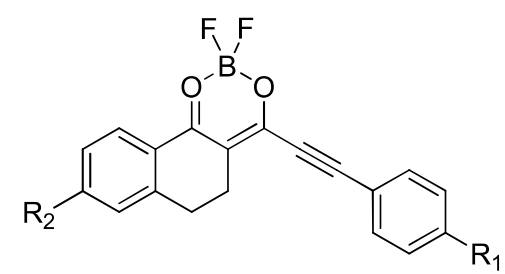

1: $R_{1}=H, R_{2}=H$

2: $\mathrm{R}_{1}=\mathrm{H}, \mathrm{R}_{2}=\mathrm{MeO}$

3: $\mathrm{R}_{1}=\mathrm{Cl}, \mathrm{R}_{2}=\mathrm{MeO}$

4: $\mathrm{R}_{1}=\mathrm{MeO}, \mathrm{R}_{2}=\mathrm{H}$

5: $\mathrm{R}_{1}=\mathrm{Me}_{2} \mathrm{~N}, \mathrm{R}_{2}=\mathrm{H}$<smiles>COc1ccc2c(c1)CC/C(=C(/C#Cc1cc3ccccc3c3ccccc13)OP(F)F)C2=O</smiles>

6

7<smiles></smiles>

M'1: $\mathrm{R}_{1}=\mathrm{H}$

M'4: $\mathrm{R}_{1}=\mathrm{MeO}$<smiles></smiles>

M'6<smiles>CC(C#Cc1ccccc1)=CC(=O)c1ccccc1</smiles>

M1<smiles></smiles>

MC4<smiles>COc1ccc2cc(/C=C/C3=C(C(=O)OB(F)F)CCc4ccccc4C3=O)ccc2c1</smiles>

MC6

Chart 1. Structures of the boron difluoride dyes investigated and discussed herein. 


\section{Experimental}

Materials and Instrumentation. All solvents for synthesis were of analytic grade. Spectroscopy measurements were carried out with spectroscopic grade solvents. The complexes 1,[36] M1,[36] M'1,[34] M'4[34] and M'6[34] were previously. NMR spectra $\left({ }^{1} \mathrm{H},{ }^{13} \mathrm{C},{ }^{19} \mathrm{~F}\right)$ were recorded at room temperature on a BRUKER AC 250 or Avance III 500 operating at 400 or 500,100 or 125,425 or 470 , and $54 \mathrm{MHz}$ for ${ }^{1} \mathrm{H},{ }^{13} \mathrm{C},{ }^{19} \mathrm{~F}$, and ${ }^{11} \mathrm{~B}$ respectively. Data are listed in parts per million (ppm) and are reported relative to tetramethylsilane $\left({ }^{1} \mathrm{H}\right.$ and $\left.{ }^{13} \mathrm{C}\right)$; residual solvent peaks of the deuterated solvents were used as internal standards. Mass spectra were realized in Spectropole de Marseille (http://www.spectropole.fr/) and at Faculty of Chemistry and Chemical Technology, University of Ljubljana on TOF LC/MS spectrometer. Solid-state spectra and fluorescence quantum yields were measured using an integrating sphere. UV-Vis-absorption spectra were measured on a Varian Cary 50. Emission spectra were measured on a Horiba-JobinYvon Fluorolog-3 spectrofluorimeter that was equipped with a three-slit double-grating excitation and a spectrograph emission monochromator with dispersions of $2.1 \mathrm{~nm} . \mathrm{mm}^{-1}$ (1200 grooves. $\mathrm{mm}^{-1}$ ). Steady-state luminescence excitation was done using unpolarized light from a 450W xenon CW lamp and detected at an angle of $90^{\circ}$ for dilute-solution measurements (10 mm quartz cell) and with a red-sensitive Hamamatsu R928 photomultiplier tube. Special care was taken to correct emission spectra that were obtained with the latter device. The detector was corrected according to the procedure described by Parker et al..[37] The observed photomultiplier output $A_{1}$ was recorded at a wavelength $\lambda$, which corresponds to the apparent emission spectrum. $A_{1}$ is given by $A_{1}=\left(F_{1}\right)\left(S_{1}\right) / \lambda^{2}$, where $F_{1}$ and $S_{1}$ are, respectively, the corrected emission spectrum and the spectroscopic sensitivity factor of the monochromatorphotomultiplier setup.

To calculate $S_{l}$, we used $4-N, N$-dimethylamino-4'-nitrostilbene (DMANS) as a standard fluorophore for which its corrected emission spectrum has been precisely determined.[38] Luminescence quantum yields $\left(\Phi_{\mathrm{f}}\right)$ were measured in dilute DCM solutions with an absorbance below 0.1 using $\Phi_{\mathrm{fx}} / \Phi_{\mathrm{fr}}=\left[O D_{\mathrm{r}}(\lambda) / O D_{\mathrm{x}}(\lambda)\right]\left[I_{\mathrm{x}} / I_{\mathrm{r}}\right]\left[n_{\mathrm{x}} / n_{\mathrm{r}}\right]$. where $O D(\lambda)$ is the absorbance at the excitation wavelength $(\lambda), n$ the refractive index, and $I$ the integrated luminescence intensity. The " $r$ " and " $\mathrm{x}$ " subscripts stand for reference and sample, respectively. The luminescence quantum yields were not corrected by the refractive indices. We used as reference ruthenium trisbipyridine bischloride ( $\Phi_{\mathrm{fr}}=0.021$ in water).[39] 
Time-resolved fluorescence measurements were carried out using a Noncolinear Optical Parametric Amplifier (NOPA) pumped by a fiber femtosecond laser (Amplitude Systemes Tangerine), and a streak camera (Hamamatsu PLP system) with a time resolution of about 10 ps. The pulse duration was $100 \mathrm{fs}$ and the repetition rate was $10 \mathrm{kHz}$. The pumping intensity was controlled using a set of neutral densities. The PL was collected at the magic angle between the polarization of the excitation light and the polarization of the detected polarized light in order to avoid any polarization anisotropy effect; the reported $\tau$ values are given with an estimated uncertainty of about $10 \%$.

Cyclic voltammetric (CV) data were acquired using a BAS 100 Potentiostat (Bioanalytical Systems) and a PC computer containing BAS100W software (v2.3). A three-electrode system with a Pt working electrode (diameter $1.6 \mathrm{~mm}$ ), a Pt counter electrode and an $\mathrm{Ag} / \mathrm{AgCl}$ (with $3 \mathrm{M} \mathrm{NaCl}$ filling solution) reference electrode was used. $\left[(n-\mathrm{Bu})_{4} \mathrm{~N}\right] \mathrm{PF}_{6} \quad(0.1 \mathrm{M}$ in dichloromethane) served as an inert electrolyte. Cyclic voltammograms were recorded at a scan rate of $100 \mathrm{mV} . \mathrm{s}^{-1}$. Ferrocene was used as internal standard.[40]

All DFT/TD-DFT calculations were carried with the Gaussian09 (version D.01) program,[41] tightening self-consistent field convergence thresholds $\left(10^{-10} \mathrm{au}\right)$ and geometry optimization $\left(10^{-5} \mathrm{au}\right)$ convergence thresholds. For all calculations, the hybrid PBE0[42, 43] functional has been used. The $6-311 \mathrm{G}(2 \mathrm{~d}, \mathrm{p})$ atomic basis set has been employed for geometry and frequency calculations, whereas the $6-311+\mathrm{G}(2 \mathrm{~d}, \mathrm{p})$ atomic basis set was used for determining electronic transitions. Solvent effects were included according to the Polarizable Continuum Model[44] using a linear-response nonequilibrium approach for the TD-DFT step.[45, 46]

\section{Synthetic procedures}

General synthetic procedure

A pre-cooled solution $\left(-78{ }^{\circ} \mathrm{C}\right)$ of phenylacetylene $(326 \mathrm{mg}, 3.2 \mathrm{mmol})$ in dry THF $(10 \mathrm{~mL})$ was treated dropwise with the $n$-BuLi solution $(1.6 \mathrm{M}, 2.0 \mathrm{~mL}, 3.2 \mathrm{mmol})$. Reaction mixture was stirred at $-78{ }^{\circ} \mathrm{C}$ for 30 minutes and then dropwise added to the pre-cooled $\left(-78{ }^{\circ} \mathrm{C}\right)$ solution of 4-ethoxy-2,2-difluoro-8-methoxy-5,6-dihydro- $2 H$ - $2 \lambda^{4}, 3 \lambda^{3}$-naphtho[1,2d] $[1,3,2]$ dioxaborinine $(977 \mathrm{mg}, 3.30 \mathrm{mmol})$ in dry THF $(20 \mathrm{~mL})$. The reaction mixture was stirred at $-78{ }^{\circ} \mathrm{C}$ for 30 minutes and then quenched with $\mathrm{HCl}(1 \mathrm{M}, 2.5 \mathrm{~mL})$. The product was extracted into DCM $(3 \times 10 \mathrm{~mL})$, dried over $\mathrm{MgSO}_{4}$ and evaporated. 
2,2-difluoro-8-methoxy-4-(phenylethynyl)-5,6-dihydro- $2 H-2 \lambda^{4}, 3 \lambda^{3}$-naphtho[1,2-

d] $[1,3,2]$ dioxaborinine (2)

The crude product was treated with $\mathrm{Et}_{2} \mathrm{O}(10 \mathrm{~mL})$ and filtered of yielding $(912 \mathrm{mg}, 81 \%)$ of pure product. $R_{\mathrm{f}}=0.22$ (petroleum ether-EtOAc $=5 / 3$ ). IR $\left(\mathrm{KBr}, \mathrm{cm}^{-1}\right): 2200,1600,1543$, $1500,1484,1461,1432,1391,1321,1281,1249,1138,1076,1041,1015 .{ }^{1} \mathrm{H}$ NMR (500 $\mathrm{MHz}): \delta 8.14\left(\mathrm{~d},{ }^{3} J=9.0 \mathrm{~Hz}, 1 \mathrm{H}\right), 7.64-7.62(\mathrm{~m}, 2 \mathrm{H}), 7.53-7.49(\mathrm{~m}, 1 \mathrm{H}), 7.44-7.41(\mathrm{~m}, 2 \mathrm{H})$, $6.91\left(\mathrm{dd},{ }^{3} J=9.0,{ }^{4} J=2.5 \mathrm{~Hz}, 1 \mathrm{H}\right), 6.80\left(\mathrm{~d},{ }^{4} J=2.5 \mathrm{~Hz}, 1 \mathrm{H}\right), 3.01-2.92(\mathrm{~m}, 4 \mathrm{H}) .{ }^{11} \mathrm{~B}$ NMR (53.7 MHz): $\delta$ 0.75. ${ }^{19} \mathrm{~F}$ NMR (470.4 MHz): $\delta-140.2 .{ }^{13} \mathrm{C}$ NMR (75.5 MHz): $\delta$ 179.2, 166.4, 161.9, 147.6, 133.0, 131.5, 131.4, 128.8, 120.9, 119.7, 114.0, 113.6, 110.7, 104.1, 84.1, 55.9, 28.1, 22.7. HRMS (ESI+, $\left[\mathrm{MNH}_{4}\right]^{+}$) Calcd for $\mathrm{C}_{20} \mathrm{H}_{19} \mathrm{BF}_{2} \mathrm{NO}_{3}: 370.1426$. Found 370.1422.

4-((4-chlorophenyl)ethynyl)-2,2-difluoro-8-methoxy-5,6-dihydro- $2 H-2 \lambda^{4}, 3 \lambda^{3}$-naphtho[1,2d] $[1,3,2]$ dioxaborinine (3)

The crude product was recrystallized from MeCN yielding $(853 \mathrm{mg}, 69 \%)$ pure product. $R_{\mathrm{f}}=$ 0.27 (petroleum ether-EtOAc $=5 / 3)$. IR $\left(\mathrm{KBr}, \mathrm{cm}^{-1}\right): 2194,1621,1570,1536,1399,1154$, 1062, 823. ${ }^{1} \mathrm{H}$ NMR (500 MHz): $\delta 8.16\left(\mathrm{~d},{ }^{3} J=9.5 \mathrm{~Hz}, 1 \mathrm{H}\right), 7.56\left(\mathrm{AA}^{\prime} \mathrm{BB}^{\prime},{ }^{3} J=8.5 \mathrm{~Hz}, 2 \mathrm{H}\right)$, $7.42\left(\mathrm{AA}^{\prime} \mathrm{BB}\right.$ ', $\left.{ }^{3} J=8.5 \mathrm{~Hz}, 2 \mathrm{H}\right), 6.92\left(\mathrm{dd},{ }^{3} J=9.0,{ }^{4} J=2.5 \mathrm{~Hz}, 1 \mathrm{H}\right), 6.79\left(\mathrm{~d},{ }^{4} J=2.5 \mathrm{~Hz}\right.$, $1 \mathrm{H}), 3.93(\mathrm{~s}, 3 \mathrm{H}), 3.01-2.91(\mathrm{~m}, 4 \mathrm{H}) .{ }^{11} \mathrm{~B} \mathrm{NMR}(53.7 \mathrm{MHz}): \delta-0.67 .{ }^{19} \mathrm{~F}$ NMR $(470.4 \mathrm{MHz})$ : $\delta-159.26 .{ }^{13} \mathrm{C}$ NMR $(75.5 \mathrm{MHz}): \delta 179.5,166.5,161.4,147.7,137.8,134.1,131.7,129.3$, 121.0, 118.2, 114.0, 113.6, 110.8, 102.4, 84.8, 55.9, 28.1, 22.7. HRMS (ESI+, [M-F] $\left.{ }^{+}\right)$Calcd for $\mathrm{C}_{20} \mathrm{H}_{13} \mathrm{BClFO}_{3}: 367.0709$. Found 367.0697. Anal. Calcd for: $\mathrm{C}_{20} \mathrm{H}_{14} \mathrm{BClF}_{2} \mathrm{O}_{3}: \mathrm{C}, 62.14 ; \mathrm{H}$, 3.65. Found: C, 62.38, H, 3.55.

2,2-difluoro-4-( $p$-tolylethynyl)-5,6-dihydro- $2 H-2 \lambda^{4}, 3 \lambda^{3}$-naphtho[1,2- $\left.d\right][1,3,2]$ dioxaborinine (4).

The crude product was treated with DCM (3 mL) and filtered off yielding ( $822 \mathrm{mg}, 73 \%$ ) pure product. $R_{\mathrm{f}}=0.20$ (petroleum ether-EtOAc $\left.=5 / 3\right) . \mathrm{IR}\left(\mathrm{KBr}, \mathrm{cm}^{-1}\right): 2188,1687,1583,1543$, $1511,1360,1345,1331,1297,1276,1260,1245,1225,1165,1144,1018 .{ }^{1} \mathrm{H}$ NMR (500 MHz): $\delta 8.16\left(\mathrm{~d},{ }^{3} J=7.5 \mathrm{~Hz}, 1 \mathrm{H}\right), 7.61-7.57(\mathrm{~m}, 3 \mathrm{H}), 7.41\left(\mathrm{dd},{ }^{3} J=7.5,{ }^{3} J=7.5 \mathrm{~Hz}, 1 \mathrm{H}\right)$, $7.32\left(\mathrm{~d},{ }^{3} J=7.5 \mathrm{~Hz}, 1 \mathrm{H}\right), 6.95\left(\mathrm{AA}^{\prime} \mathrm{BB},{ }^{3} J=9.0 \mathrm{~Hz}, 2 \mathrm{H}\right), 3.04-2.94(\mathrm{~m}, 4 \mathrm{H}) .{ }^{11} \mathrm{~B}$ NMR (53.7 MHz): $\delta$ 0.84. ${ }^{19} \mathrm{~F}$ NMR (470.4 MHz): $\delta-139.6 .{ }^{13} \mathrm{C}$ NMR (75.5 MHz): $\delta 179.0,165.1$, $162.7,143.9,135.7,135.5,128.4,128.4,128.3,127.7,114.7,111.2,110.9,107.7,84.6,55.6$, 27.6, 22.5. HRMS (ESI+, $\left[\mathrm{MNH}_{4}\right]^{+}$) Calcd for $\mathrm{C}_{20} \mathrm{H}_{19} \mathrm{BF}_{2} \mathrm{NO}_{3}: 370.1426$. Found 370.1426. 4-((2,2-difluoro-5,6-dihydro- $2 H-2 \lambda^{4}, 3 \lambda^{3}$-naphtho[1,2- $\left.d\right][1,3,2]$ dioxaborinin-4-yl)ethynyl)$N, N$-dimethylaniline (5) 
The crude product was treated with EtOAc $(10 \mathrm{~mL})$ and filtered off under reduced pressure yielding $(596 \mathrm{mg}, 51 \%)$ pure product. $R_{\mathrm{f}}=0.10$ (petroleum ether-EtOAc $\left.=5 / 3\right) . \mathrm{IR}\left(\mathrm{KBr}, \mathrm{cm}^{-}\right.$ $\left.{ }^{1}\right): 2162,1599,1530,1483,1453,1346,1330,1275,1175,1135,1060,1027 .{ }^{1} \mathrm{H}$ NMR (500 MHz): $\delta 8.145\left(\mathrm{~d},{ }^{3} J=7.5 \mathrm{~Hz}, 1 \mathrm{H}\right), 7.57-7.51(\mathrm{~m}, 3 \mathrm{H}), 7.40\left(\mathrm{dd},{ }^{3} J=7.5,{ }^{3} J=7.5 \mathrm{~Hz}, 1 \mathrm{H}\right)$, $7.29\left(\mathrm{~d},{ }^{3} J=7.5 \mathrm{~Hz}, 1 \mathrm{H}\right), 6.67$ (AA'BB', $\left.{ }^{3} J=9.0 \mathrm{~Hz} .2 \mathrm{H}\right) 3.09$ (s, 6H), 3.02-2.90 (m, 4H). ${ }^{11} \mathrm{~B}$ NMR (53.7 MHz): $\delta 0.84 .{ }^{19} \mathrm{~F}$ NMR (470.4 MHz): $\delta-140.2 .{ }^{13} \mathrm{C}$ NMR $(75.5 \mathrm{MHz}): \delta$ $176.9,165.6,152.5,143.3,135.7,134.9,128.8,128.2,128.0,127.5,112.7,111.7,110.0$, 104.8, 86.79, 40.1, 27.7, 22.4. HRMS (ESI+, $[\mathrm{MH}]^{+}$) Calcd for $\mathrm{C}_{21} \mathrm{H}_{19} \mathrm{BF}_{2} \mathrm{NO}_{2}: 366.1477$. Found 366.1478.

2,2-difluoro-4-((6-methoxynaphthalen-2-yl)ethynyl)-5,6-dihydro- $2 H-2 \lambda^{4}, 3 \lambda^{3}$-naphtho[1,2d] $[1,3,2]$ dioxaborinine $(6)$

The crude product was recrystallized from DCM yielding $(850 \mathrm{mg}, 66 \%)$ pure product. $R_{\mathrm{f}}=$ 0.15 (petroleum ether-EtOAc $=5 / 3)$. IR $\left(\mathrm{KBr}, \mathrm{cm}^{-1}\right): 2185,1619,1601,1547,1504,1477$, $1453,1434,1348,1328,1245,1041,1023,855 .{ }^{1} \mathrm{H}$ NMR $(500 \mathrm{MHz}): \delta 8.19\left(\mathrm{~d},{ }^{3} J=8.0 \mathrm{~Hz}\right.$, $1 \mathrm{H}), 8.16(\mathrm{~s}, 1 \mathrm{H}), 7.78\left(\mathrm{~d},{ }^{3} J=8.0 \mathrm{~Hz}, 1 \mathrm{H}\right), 7.77\left(\mathrm{~d},{ }^{3} J=8.0 \mathrm{~Hz}, 1 \mathrm{H}\right), 7.62-7.58(\mathrm{~m}, 2 \mathrm{H}) 7.43$ (dd, $\left.{ }^{3} J=8.0,{ }^{3} J=8.0 \mathrm{~Hz}, 1 \mathrm{H}\right), 7.33\left(\mathrm{~d},{ }^{3} J=7.5 \mathrm{~Hz}, 1 \mathrm{H}\right), 7.23\left(\mathrm{dd},{ }^{3} J=9.0,{ }^{4} J=2.0 \mathrm{~Hz}, 1 \mathrm{H}\right)$, $7.15\left(\mathrm{~d},{ }^{4} J=2.0 \mathrm{~Hz}, 1 \mathrm{H}\right), 3.96(\mathrm{~s}, 3 \mathrm{H}), 3.08-2.99(\mathrm{~m}, 4 \mathrm{H}) .{ }^{11} \mathrm{~B}$ NMR $(53.7 \mathrm{MHz}): \delta 0.86 .{ }^{19} \mathrm{~F}$ NMR (470.4 MHz): $\delta-139.5 .{ }^{13} \mathrm{C}$ NMR (75.5 MHz): $\delta 179.3,164.9,159.9,144.0,136.2$, $135.8,134.9,130.1,128.9,128.44,128.40,128.4,128.1,127.8,127.5,120.3,114.0,111.2$, 107.6, 106.0, 84.7, 55.5, 27.6, 22.5. HRMS (ESI+, $\left[\mathrm{MNH}_{4}\right]^{+}$) Calcd for $\mathrm{C}_{24} \mathrm{H}_{21} \mathrm{BF}_{2} \mathrm{NO}_{3}$ : 420.1583. Found 420.1584.

2,2-difluoro-8-methoxy-4-(phenanthren-9-ylethynyl)-5,6-dihydro-2H-2 $\lambda^{4}, 3 \lambda^{3}$-naphtho[1,2d] $[1,3,2]$ dioxaborinine $(7)$

The crude product was recrystallized from DCM yielding $(1.012 \mathrm{mg}, 70 \%)$ pure product. $R_{\mathrm{f}}=$ 0.20 (petroleum ether-EtOAc $=5 / 3) . \mathrm{IR}\left(\mathrm{KBr}, \mathrm{cm}^{-1}\right): 2906,2839,2338,1611,1573,1531$, 1477, 1426, 1283, 1026. ${ }^{1} \mathrm{H}$ NMR (500 MHz): $\delta$ 8.74-8.69 (m, 2H), 8.42-8.40 (m, 1H), 8.27 (s, 1H), $8.20\left(\mathrm{~d},{ }^{3} J=9.0 \mathrm{~Hz}, 1 \mathrm{H}\right), 7.94\left(\mathrm{~d},{ }^{3} J=8.0 \mathrm{~Hz}, 1 \mathrm{H}\right), 7.79-7.74(\mathrm{~m}, 3 \mathrm{H}), 7.67\left(\mathrm{t},{ }^{3} J=\right.$ $7.5 \mathrm{~Hz}, 1 \mathrm{H}), 6.94\left(\mathrm{dd},{ }^{3} J=9.0 \mathrm{~Hz},{ }^{4} J=2.5,1 \mathrm{H}\right), 6.82\left(\mathrm{~d},{ }^{4} J=2.5 \mathrm{~Hz}, 1 \mathrm{H}\right), 3.94(\mathrm{~s}, 3 \mathrm{H}), 3.13-$ $3.06(\mathrm{~m}, 4 \mathrm{H}) .{ }^{11} \mathrm{~B}$ NMR $(53.7 \mathrm{MHz}): \delta 0.85 .{ }^{19} \mathrm{~F}$ NMR $(470.4 \mathrm{MHz}): \delta-140.2 .{ }^{13} \mathrm{C} \mathrm{NMR}$ (75.5 MHz): $\delta 179.4,166.4,162.0,147.5,136.2,131.6,130.6,130.3,130.2,130.0,129.4$, $129.3,127.8,127.4,126.5,123.1,122.9,121.1,116.4113 .9,113.7,110.7,102.9,88.5,55.9$, 22.9, 28.2. HRMS (ESI+, $[\mathrm{M}-\mathrm{F}]^{+}$) Calcd for $\mathrm{C}_{28} \mathrm{H}_{19} \mathrm{BFO}_{3}$ : 432.1442. Found 432.1445. 
2,2-difluoro-4-(4-methoxystyryl)-5,6-dihydro-2 $H-2 \lambda^{4}, 3 \lambda^{3}$-naphtho[1,2- $\left.d\right][1,3,2]$ dioxaborinin3-ium-2-uide (MC4)

The crude product was solubilized in a minimum of DCM $(10 \mathrm{~mL})$, precipitated with $\mathrm{Et}_{2} \mathrm{O}$ and filtered off yielding $(0.715 \mathrm{mg}, 62 \%)$ pure product. $R_{\mathrm{f}}=0.2$ (petroleum ether-DCM = 2/1). ${ }^{1} \mathrm{H}$ NMR (400 MHz): $\delta$ 8.19-8.16 (m, 2H), $7.64\left(\mathrm{~d},{ }^{3} J=8.8 \mathrm{~Hz}, 2 \mathrm{H}\right), 7.55\left(\mathrm{dt},{ }^{3} J=7.3\right.$ $\left.\mathrm{Hz},{ }^{4} J=1.2 \mathrm{~Hz}, 1 \mathrm{H}\right), 7.40\left(\mathrm{t},{ }^{3} J=7.9 \mathrm{~Hz}, 1 \mathrm{H}\right), 7.29\left(\mathrm{~d},{ }^{3} J=8.0 \mathrm{~Hz}, 1 \mathrm{H}\right), 6.96(\mathrm{~m}, 3 \mathrm{H}), 3.89$ (s, 3H), 3.02-2.88 (m, 4H). ${ }^{13} \mathrm{C}$ NMR (100 MHz): $\delta 185.7,176.4,161.1,141.7,140.2,132.7$, 132.3, 129.7, 128.2, 127.6, 126.9, 126.4, 116.7, 114.3, 106.6, 55.3, 28.3, 22.5. HRMS (ESI+, $[\mathrm{M}+\mathrm{Na}]^{+}$) Calcd for $\mathrm{C}_{20} \mathrm{H}_{17} \mathrm{BF}_{2} \mathrm{O}_{3} \mathrm{Na}^{+}:$377.1137. Found 377.1139.

2,2-difluoro-4-(2-(6-methoxynaphthalen-2-yl)vinyl)-5,6-dihydro- $2 H-2 \lambda^{4}, 3 \lambda^{3}$-naphtho[1,2d] [1,3,2]dioxaborinin-3-ium-2-uide (MC6)

The crude product was solubilized in a minimum of DCM $(10 \mathrm{~mL})$, precipitated with $\mathrm{Et}_{2} \mathrm{O}$ and filtered off yielding $(0.862 \mathrm{mg}, 78 \%)$ pure product. $R_{\mathrm{f}}=0.4$ (petroleum ether-DCM $=$ 1/1). ${ }^{1} \mathrm{H}$ NMR (400 MHz): $\delta 8.30\left(\mathrm{~d},{ }^{3} J=15.2 \mathrm{~Hz}, 1 \mathrm{H}\right), 8.16\left(\mathrm{~d},{ }^{3} J=7.6 \mathrm{~Hz}, 1 \mathrm{H}\right), 8.00$ (s, $1 \mathrm{H}), 7.80\left(\mathrm{~d},{ }^{3} J=8.8 \mathrm{~Hz}, 1 \mathrm{H}\right), 7.77-7.71(\mathrm{~m}, 2 \mathrm{H}), 7.55\left(\mathrm{dt},{ }^{3} J=7.6 \mathrm{~Hz},{ }^{4} J=1.6 \mathrm{~Hz}, 1 \mathrm{H}\right), 7.39$ $\left(\mathrm{d},{ }^{3} J=7.6 \mathrm{~Hz}, 1 \mathrm{H}\right), 7.29\left(\mathrm{~d},{ }^{3} J=7.6 \mathrm{~Hz}, 1 \mathrm{H}\right), 7.20\left(\mathrm{dd},{ }^{3} J=8.8 \mathrm{~Hz},{ }^{4} J=2.4 \mathrm{~Hz}, 1 \mathrm{H}\right), 7.11$ $7.15(\mathrm{~m}, 2 \mathrm{H}), 3.95$ (s, 3H), 3.01-2.91 (m, 4H). ${ }^{13} \mathrm{C}$ NMR (100 MHz): $\delta$ 177.5, 159.8, 148.9, $143.0,136.8,135.7,134.9,132.4,130.8,129.8,129.2,128.7,128.0,127.9,127.6,124.5$, 119.9, 115.7, 106.2, 55.6, 27.6, 21.3. HRMS (ESI+, $[\mathrm{M}+\mathrm{Na}]^{+}$) Calcd for $\mathrm{C}_{24} \mathrm{H}_{19} \mathrm{BF}_{2} \mathrm{O}_{3} \mathrm{Na}^{+}$: 427.1293. Found 427.1294.

\section{Results and discussion}

\section{Synthesis and X-Ray crystal structures}

The synthesis of the model hemicurcuminoid boron difluorides was achieved as reported elsewhere[34] using benzoylacetone or 2-acetyl-1-tetralone as starting materials, boron oxide as chelate for the acetylacetone moiety and the appropriate aldehyde in an aldol-like extension of the conjugation. The compounds containing acetylene function were prepared in a similar way that was reported previously.[36]

Crystals suitable for X-Ray diffraction of 3, 4, 6 and 7 were obtained by crystallization from DCM or mixture of solvents DCM and EtOAc. Detailed crystallographic parameters are listed in Table $\mathrm{S} 1$ in the supporting information (SI). While 3 (P-1) crystallizes in the triclinic system, 4, 6 and 7 (P21/c) crystallize in a monoclinic space group. In addition, the 
dioxaborine rings in these four compounds present almost the same bond lengths (Table S2) independently of the substituent pattern of the tetralone phenyl ring and the phenyl acetylenic ring. We defined $\psi$ as the angle between the plane of phenyl ring belonging the tetralone and that of the terminal aryl group. While complexes 3 and 7 show $\psi$ values of $2.0^{\circ}$ and $3.8^{\circ}$, respectively, and are therefore planar, complexes $\mathbf{4}$ and $\mathbf{6}$ are distorted with $\psi$ values of $20.1^{\circ}$ and $37.2^{\circ}$, respectively. It has to be noted that the endocyclic $\mathrm{C}-\mathrm{C}$ bond of the Acac moiety is always slightly longer than the exocyclic C-C bond (1.39-1.40 $\AA$ versus $1.37-1.38 \AA$, Table S2), suggesting that the latter has a stronger double bond character. This localization of the double bond is also consistent with the C-O distances that are 1.29-1.30 $\AA$ for the endocyclic C-O versus $1.31 \AA$ (for the exocyclic C-O (Table S2).

All borondifluoride complexes are $\pi$-stacked forming head-to-tail dimers with the dioxaborine unit of one molecule lying above the triple bond of the donor group (side B) of the adjacent molecule. The intra-dimer distances between average molecular planes are short for the four compounds, close to the van der Waals contact distance, indicating a tight packing as generally observed for dipolar dyes in the crystal. For 3, this distance equals $3.547 \AA$, two adjacent dimers being separated by $3.592 \AA$. For dyes 7 and $\mathbf{4}$, the intra-dimer distance are shorter (3.382 and $3.509 \AA$, respectively). Dye 6 shows the most densely packed solid with an interplanar distance of $3.173 \AA$.

\section{Electrochemistry}

The electrochemical potentials of the first oxidation and reduction processes of the complexes were determined in dichloromethane $(\mathrm{DCM})$ containing $0.1 \mathrm{M}$ of $(n-\mathrm{Bu})_{4} \mathrm{NPF}_{6}$. The data are collected in Table 1 ( $\mathrm{E}_{1 / 2}$ vs. ferrocene/ferrocenium). The first oxidation can be attributed to the electron donor moiety of the systems (side B) while the first reduction corresponds to the acceptor moiety (dioxaborine ring).

As can be seen from Table 1, by comparing 4 and 6 with MC4 and MC6, one notices that the introduction of a triple bond results in a less negative reduction potential (by 40 and $70 \mathrm{mV}$, respectively). This is associated with a higher oxidation potential for $\mathbf{4}$ and $\mathbf{6}$. These effects can be attributed to the acceptor character of the triple bond. The same trend is observed for the reduction of M1 versus M'1 (one can notice that, due to the absence of donor group on those latter dyes, no oxidation could be detected). The bridging of the dioxaborine ring via the $\mathrm{CH}_{2}-\mathrm{CH}_{2}$ unit makes the tetralone-based MC4 and MC6 easier to reduce compared to M'4 and M'6, but the reverse effect is noticed for the ethynylene compounds $\mathbf{1}$ and M1. In the 
same time, an easier oxidation was observed for MC4 and MC6, yielding a much lower electrochemical gap for the dyes containing tetralone. Finally, as noticed in the $\mathrm{BF}_{2}-$ hemicurcuminoid series, [34] increasing the strength of the electron donor moiety results in lower oxidation potential values. This effect is accompanied by a slight cathodic shift of the reduction potential.

It can also be seen from Table 1 that the Gibbs free energy calculated for photoinduced electron transfer using the Rehm-Weller equation is negative for most of the borondifluoride complexes, which indicates a thermodynamically-allowed photoinduced electron transfer process which would occur from the donor moiety (side B) to the dioxaborine part in these molecules in polar medium such as DCM solution.

Table 1. Oxidation and reduction half-wave potential values for the studied dioxaborine derivatives $(10 \mu \mathrm{M})$ in dichloromethane solution using tetrabutylammonium hexafluorophosphate as electrolyte $(100 \mu \mathrm{M})$, the values are given in volt $v s . \mathrm{Fc} / \mathrm{Fc}^{+}$.

\begin{tabular}{cccccc}
\hline Cmpd & $E^{\mathrm{red}}(1) / \mathrm{V}$ & $E^{\mathrm{ox}}(1) / \mathrm{V}$ & $E_{\mathrm{g}}{ }^{a} / \mathrm{V}$ & $E_{0-0}{ }^{b} / \mathrm{eV}$ & $\Delta G^{c} / \mathrm{eV}$ \\
\hline $\mathbf{1}$ & -1.21 & $-^{d}$ & $-^{d}$ & 2.76 & $-^{d}$ \\
$\mathbf{2}$ & -1.33 & 1.51 & 2.84 & 2.67 & 0.1 \\
$\mathbf{3}$ & -1.27 & 1.46 & 2.73 & 2.63 & 0 \\
$\mathbf{4}$ & -1.27 & 1.47 & 2.74 & 2.62 & 0 \\
$\mathbf{5}$ & -1.35 & 0.65 & 2.00 & 2.16 & -0.2 \\
$\mathbf{6}$ & -1.18 & 1.22 & 2.40 & 2.51 & -0.2 \\
$\mathbf{7}$ & -1.26 & 1.04 & 2.30 & 2.53 & -0.3 \\
M1 & -1.17 & ${ }^{d}$ & $-{ }^{d}$ & 2.97 & $-{ }^{d}$ \\
MC4 & -1.31 & 1.17 & 2.48 & 2.45 & -0.1 \\
MC6 & -1.25 & 1.02 & 2.27 & 2.37 & -0.2 \\
M'1 & -1.22 & $-{ }^{d}$ & $-{ }^{d}$ & 2.83 & $-{ }^{d}$ \\
M'4 & -1.40 & 1.33 & 2.73 & 2.58 & 0.1 \\
M'6 & -1.32 & 1.07 & 2.39 & 2.49 & -0.2 \\
\hline
\end{tabular}

${ }^{a} E_{\mathrm{g}}$, Electrochemical HOMO-LUMO gap $\Delta \mathrm{E}_{\mathrm{g}}=\left(\mathrm{E}_{1 / 2}{ }^{\mathrm{ox}}\right)_{1}-\mathrm{E}_{1 / 2}{ }^{\text {red }},{ }^{b}$ Optical gap determined from the UV-visible absorption spectra. ${ }^{c} \Delta G=E(D+/ D)-E(A / A-)-E_{00}-e^{2} / \varepsilon d .{ }^{d}$ no oxidation was observed in DCM. ${ }^{d}$ not possible to determine.

\section{Photophysical properties in solution \& (TD-)DFT calculations}

The optical properties of the dyes were measured in DCM and the spectroscopic data are collected in Table 2. The UV-vis electronic spectra displayed large molar absorption coefficient values $(\varepsilon)$ around $40000 \mathrm{M}^{-1} \mathrm{~cm}^{-1}$. They all exhibit a red shift of the lowest energy transition band when solvent polarity increases. This positive solvatochromic effect is attributed to the charge transfer character or the electronic transition from the ground- to the 
Franck-Condon excited state,[47] as observed for boron difluoride complexes of chalcones,[48, 49] curcuminoids[30, 35, 50] and hemicurcuminoids.[34] This behaviour is confirmed by the results of (TD-)DFT calculations (see computational details). Dyes 2 and 3 show a small shift like compounds 1, M1 and M'1 lacking the donor group at the B side. In those cases, the HOMO and LUMO electronic densities, not showing the typical donoracceptor behaviour (vide infra), confirm the absence of any push-pull character (see Figure 1) which can be rationalized by the smaller conjugation pathway when compared to 4.7 is slightly different since the HOMO and LUMO show a delocalisation from the phenanthrene moiety to the carbonyl group evidencing a partial CT character.

Given the odd number of $p_{z}$ carbon atomic orbitals involved in the conjugation, we can consider that these chromophores as cyanine-like systems. Figure 1 shows the HOMO-1, HOMO, LUMO and LUMO+1 representations for 1, M1, M'1 and 7. First, we clearly notice the expected $\pi-\pi^{*}$ nature of the excited states, and that both vinyl and ethynyl linkers, allow an effective conjugation between the donor and acceptor moieties. As a consequence, the HOMO orbital is mainly located on the lateral arms while the LUMO is spread over the central borondifluoride core.

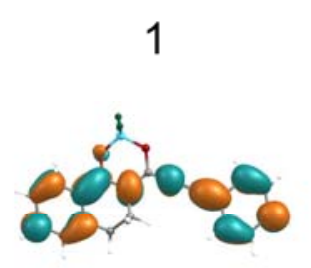

$\mathrm{LUMO}+1$

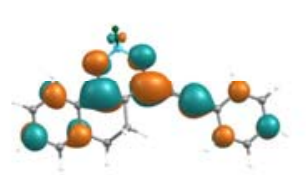

LUMO

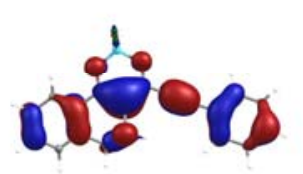

HOMO

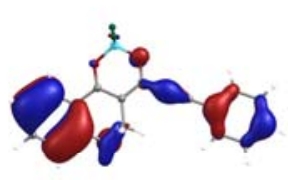

HOMO-1

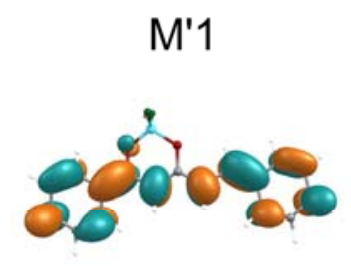

LUMO+1

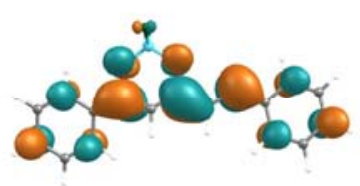

LUMO

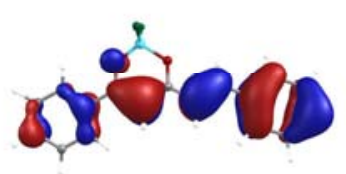

HOMO

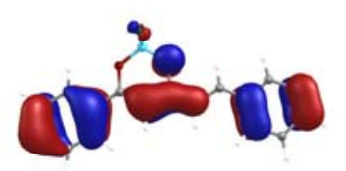

HOMO-1

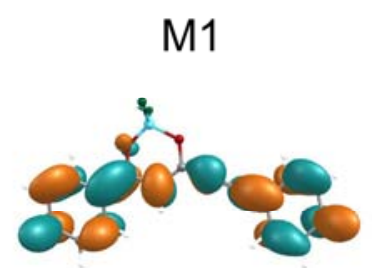

LUMO+1

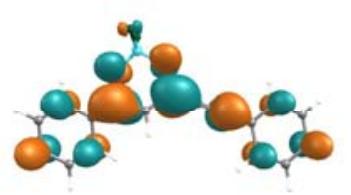

LUMO

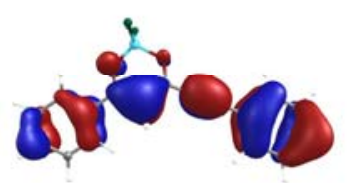

HOMO

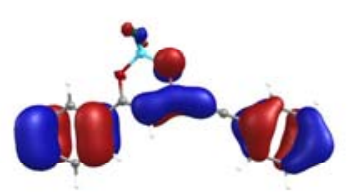

HOMO-1

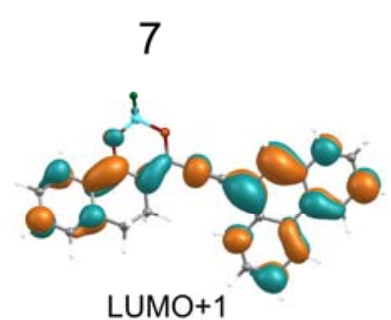

LUMO+1
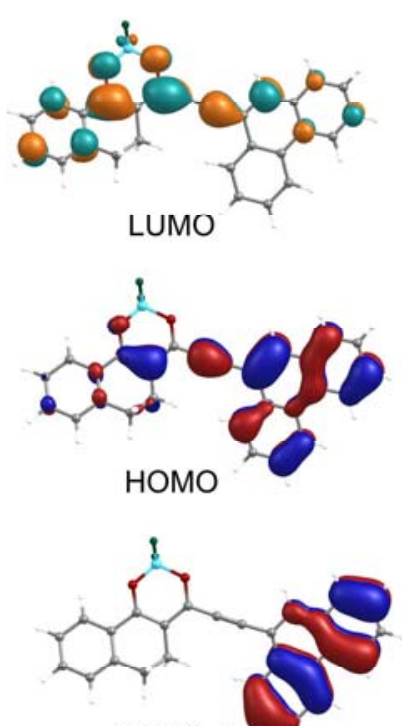

HOMO-1 
Figure 1. HOMO, HOMO-1, LUMO and LUMO+1 of chromophores 1, M'1, M1 and 7 (threshold 0.03 a.u.).

The calculated absorption data (Table S3) reveal a dominating HOMO-LUMO character of the $\mathrm{S}_{0}-\mathrm{S}_{1}$ excitations that are associated with large oscillator strengths ranging from 1.051 (1) to 1.492 (MC6). Additionally, the band gap energies are presented in Table S4 and Figure S11, where it can be noticed the higher values obtained for $1(3.7 \mathrm{eV}), \mathbf{M} 1(3.8 \mathrm{eV})$ and M1 $(3.9 \mathrm{eV})$ that can be attributed to the least donating behaviour of the phenyl ring in comparison to other substituents, resulting in lower HOMO energies. Conversely, the strong electron donor character of the dimehtylaminophenyl group attached to the $\mathrm{BF}_{2}$ moiety through an ethynyl linker makes 5 the chromophore with the smallest band gap $(3.0 \mathrm{eV})$. Remarkably, the calculated bandgap trend is in good agreement with those obtained by electrochemical and optical methodologies (Table 1).

The absorption maximum is red-shifted when increasing the donor strength of the B part up to $514 \mathrm{~nm}$ for the dimethylamino donor $\mathbf{5}$. When comparing to the dyes containing a double bond instead of the triple bond (MC4 and MC6 compared to 4 and 6, respectively), it appears that MC4 and MC6 are red shifted by 21-22 $\mathrm{nm}$ as a result of the better conjugation pathway. This is also in line with the better acceptor character of the triple bond and the electrochemical trend observed (vide supra). In addition, comparing MC4 and MC6 to hemicurcuminoid boron difluoride M'4 and M'6,[34] a red-shift of the absorption of the tetralone containing boron difluoride dyes MC4 and MC6 is observed which is in line with the more planar structure induced by the cyclic structure of the tetralone.

Table 2. Spectroscopic data and photophysical properties of the compounds recorded in DCM at room temperature ${ }^{a}$ and fluorescence properties of the powder.

\begin{tabular}{|c|c|c|c|c|c|c|c|c|c|c|c|}
\hline \multirow[b]{3}{*}{ compound } & \multirow{2}{*}{\multicolumn{2}{|c|}{$\begin{array}{c}\text { UV-vis } \\
\text { DCM }\end{array}$}} & \multicolumn{9}{|c|}{ Fluorescence } \\
\hline & & & \multicolumn{7}{|c|}{ DCM } & \multicolumn{2}{|c|}{ Powder } \\
\hline & $\lambda_{\mathrm{abs}}$ & $\varepsilon_{\text {max }}$ & $\lambda_{\mathrm{em}}$ & $\Delta v_{S T}$ & $\Phi_{\mathrm{f}}$ & $\Phi_{\mathrm{f}} \times \mathcal{E}$ & $\tau_{\mathrm{f}}$ & $k_{\mathrm{f}}$ & $k_{\mathrm{nr}}$ & $\lambda_{\mathrm{em}}$ & $\Phi_{\mathrm{f}}$ \\
\hline 1 & 431 & 40270 & 452 & 1078 & 0.83 & 33424 & 2.79 & 3.0 & 0.6 & 589 & 0.10 \\
\hline 2 & 443 & 41280 & 469 & 1251 & 0.80 & 33024 & 2.61 & 3.1 & 0.8 & 567 & 0.23 \\
\hline 3 & 445 & 39600 & 472 & 1285 & 0.72 & 28512 & 2.53 & 2.8 & 1.1 & 591 & 0.18 \\
\hline 4 & 446 & 42150 & 493 & 2138 & 0.145 & 6112 & 1.49 & 1.0 & 5.7 & 611 & 0.16 \\
\hline 5 & 514 & 47520 & - & - & - & - & - & - & - & 742 & 0.02 \\
\hline 6 & 457 & 40900 & 566 & 4214 & 0.16 & 6544 & 1.69 & 1.0 & 5.0 & 630 & 0.07 \\
\hline 7 & 465 & 39990 & 500 & 1505 & 0.425 & 16996 & 1.33 & 3.2 & 4.3 & 650 & 0.07 \\
\hline M1 & 401 & 38730 & 420 & 1128 & 0.43 & 16654 & 0.94 & 4.6 & 6.1 & 606 & 0.20 \\
\hline MC4 & 467 & 39580 & 515 & 1996 & 0.04 & 1583 & 0.24 & 1.6 & 38.4 & 635 & 0.13 \\
\hline
\end{tabular}




\section{ACCEPTED MANUSCRIPT}

$\begin{array}{llllllllllll}\text { MC6 } & 479 & 40150 & 564 & 3146 & 0.33 & 13250 & 1.60 & 2.1 & 4.2 & 666 & 0.06 \\ \text { M'1 } & 398 & 53950 & 443 & 2552 & 0.02 & 1079 & 0.10 & 2.0 & 98.0 & 544 & 0.24 \\ \text { M'4 } & 444 & 42410 & 506 & 2760 & 0.055 & 2332.5 & - & - & - & 636 & 0.11 \\ \text { M'6 } & 456 & 50410 & 566 & 4262 & 0.43 & 21676 & 2.53 & 1.7 & 2.3 & 575 & 0.08\end{array}$

${ }^{a}$ Absorption maximum wavelengths $\lambda_{\text {abs }}(\mathrm{nm})$, molar absorption coefficients $\varepsilon_{\max }\left(\mathrm{M}^{-1} \mathrm{~cm}^{-1}\right)$, fluorescence maximum wavelengths $\lambda_{\mathrm{em}}(\mathrm{nm})$, Stokes shifts $\Delta v_{S T}\left(\mathrm{~cm}^{-1}\right)$, fluorescence quantum yields $\Phi_{\mathrm{f}}$, brightness $\Phi_{\mathrm{f}} \mathrm{x} \mathcal{E}$

$\left(\mathrm{M}^{-1} \mathrm{~cm}^{-1}\right)$, fluorescence lifetimes $\tau_{\mathrm{f}}(\mathrm{ns})$, radiative $k_{\mathrm{f}}\left(10^{8} \mathrm{~s}^{-1}\right)$ and non-radiative $k_{\mathrm{nr}}=\left(1-\Phi_{\mathrm{f}}\right) / \tau_{\mathrm{f}}\left(10^{8} \mathrm{~s}^{-1}\right)$ rate constants

All compounds but 5 were found to be emissive in DCM solution with fluorescence quantum yields spanning from $2 \%$ to $83 \%$ (Table 2). Fluorescence emission was found to decay monoexponentially. Remarkably, when increasing the donor strength on the B side, the fluorescence quantum yield decreases until no emission could be detected for $\mathbf{5}$ in DCM. To get more insight into the excited state properties, fluorescence emission spectroscopy was also performed using solvent of various polarities (Figure S12 to Figure S22). The Lippert-Mataga plots are depicted in Figures S23-S25. For 5, fluorescence was efficient in solvents of low polarity only. We therefore used those data to get the Lippert-Mataga slope.

The dyes lacking a donor group (i.e. 1, M1 and M'1) or methoxy donors on the tetralone A side (i.e. $\mathbf{2}$ and 3), show low value of the slopes proving that the dipole moment of the excited state is similar to that of the ground state which is line with $\pi-\pi^{*}$ character of the $\mathrm{S}_{0}-\mathrm{S}_{1}$ transition. 7 shows a large slope value which can be attributed to the donor character of the phenanthrene moiety. For all other dyes, the Lippert-Mataga slopes are large revealing that the excited-state dipole moment is much larger than their ground-state counterparts for such push-pull systems.[51-53] For instance, 5 presents the largest slope of those dyes (ca. 23600) indicating a variation of dipole moment of the order of $c a$. 10D.

Compounds 1 and M1 containing the triple bond are more emissive than $\mathbf{M}^{\prime} \mathbf{1}$ in all solvents. The photophysical data (Tables 2, S5 and S9) show a large value of the non-radiative deactivation constant for the latter. The singlet excited state of both M1 and M'1 exhibit a very short lifetime (subnanosecond) as compared to the bridged dye 1. These observations and the fact that absorption and emission spectra are redshifted may indicate a more planar geometry for the bridged compound 1. Further, we found that M1 is more emissive than M'1 which might be attributed to her planarity of the triple bond containing dye in its excited state which results in a smaller value of $\mathrm{k}_{\mathrm{nr}}$. Except for a bathochromic shift of both absorption and emission, the photophysical properties (fluorescence quantum yield and lifetime) of $\mathbf{2}$ and $\mathbf{3}$ in solution are found to be very similar to those of $\mathbf{1}$. Indeed $\mathbf{1}-\mathbf{3}$ are highly emissive in all 
investigated solvents with fluorescence quantum yields ranging between $60 \%$ and nearly unity.

The fluorescence emission spectra of 1, 4, 5 and $\mathbf{6}$ in solution show a bathochromic shift when the electron donor strength of the para-substituent increases. This is due to the push-pull nature of the dyes giving a Lippert-Mataga slope increasing with the donor strength increases (Figure S24b). Consistently, dramatic solvatochromic changes are noticed for $\mathbf{4}$ and $\mathbf{5}$ as compared to $\mathbf{1}$ and the fluorescence quantum yields decrease considerably for $\mathbf{4}$ and $\mathbf{5}$ when solvent polarity increases. Here, it can also be noted that the fluorescence spectrum of $\mathbf{4}$ starts to show a broad and structureless emission at low energy in solvents such as acetone and acetonitrile (Figure S15b) while, for 5, starting from chloroform (Figure S16b) and in 1,1,1trichloroethane (Figures 2f and S16b), a broad and weak emission is observed. Those emissions might correspond to the radiative recombination process from a slightly emissive photo-induced electron transfer state (Figure S10). This effect already has been observed for a similar compound featuring double bond instead of the triple bond.[34] 

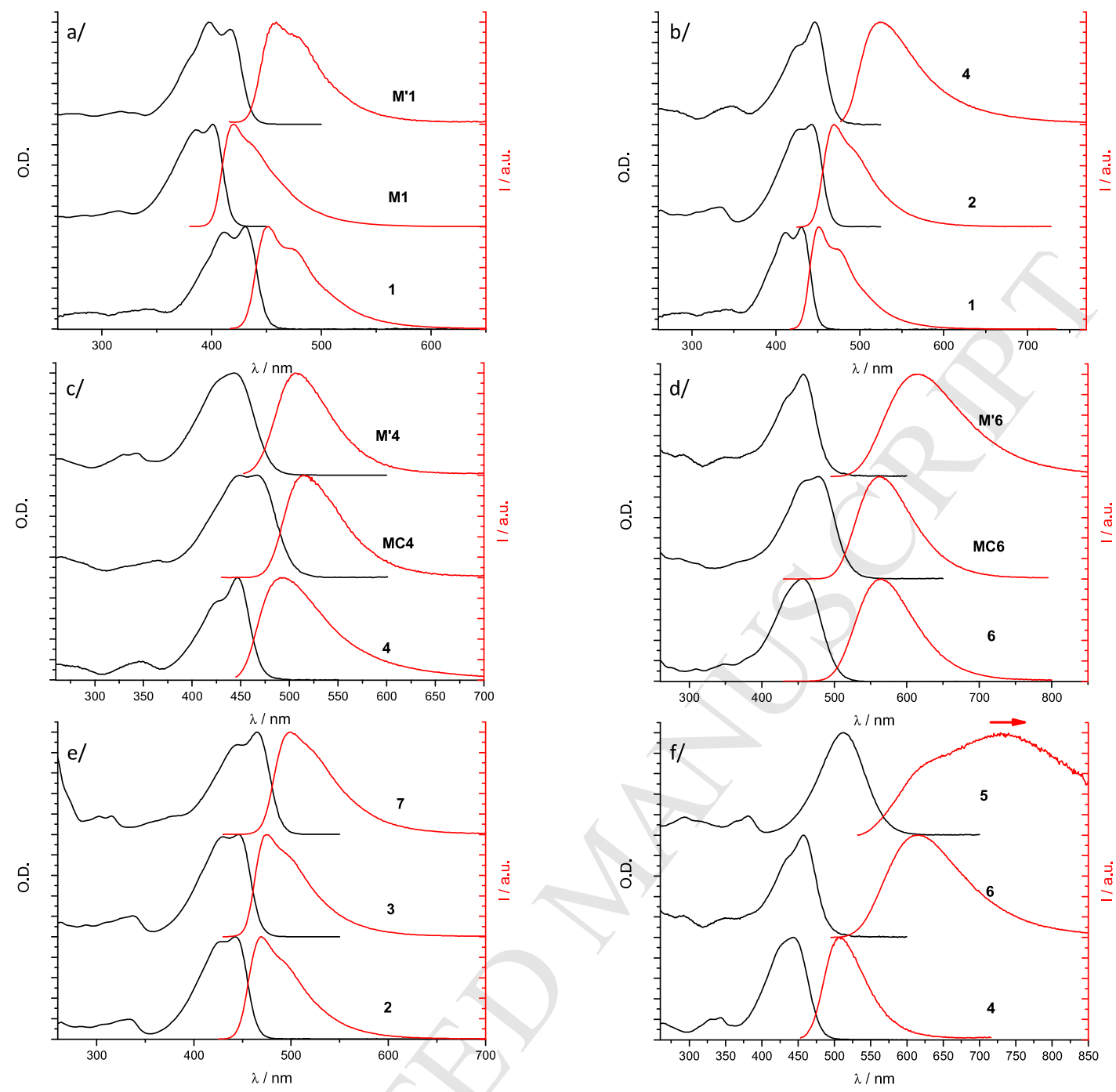

Figure 2. UV/visible absorption spectra (-) and fluorescence spectra ( - ) in DCM of a/ 1, M1 and M'1, b/ 1, 2 and 4, c/ 4, MC4 and M'4, d/ 6, MC6 and M'6, e/ 2, 3 and 7, and f/ 4, $\mathbf{6}$ and $\mathbf{5}$. Note that no emission was recorded in DCM solution, the emission of $\mathbf{5}$ presented on the figure correspond to the emission in 1,1,1-trichloroethane, the arrow means that the emission in DCM would be even more red shifted.

It is interesting to note that dye $\mathbf{4}$ containing the ethynylene unit exhibits spectra that are blue shifted as compared to the vinylene analogue MC4. The same trend is observed for 6 and MC6 but in solvents of low to moderate polarity only. This effect has already been observed in other push-pull molecules[54] and $\pi$-conjugated systems containing $\mathrm{C}(s p) / \mathrm{C}\left(s p^{2}\right)$ bonds.[55] The larger value of the Stokes shift in $\mathbf{4}$ and $\mathbf{6}$ relative to MC4 and MC6 is also consistent with previous works.[54-56] The values of the fluorescence quantum yield and lifetime for 4 and 6 (Tables S6 and S7) show a similar trend characterized by a decrease of both $\Phi_{f}$ and $\tau_{f}$ leading to a decrease of $k_{f}$ and an increase of $k_{n r}$ for 4 (more or less constant for 
6) when the solvent polarity increases. This may be attributed to a more pronounced charge transfer character of the emitting state for the ethynylene-containing molecules. The trend is opposite for the bridged vinylene analogues, MC4 and MC6 (Table S10), for which $k_{f}$ slightly increases and $k_{n r}$ decreases when the solvent polarity increases. These effects may arise from a more allowed radiative transition in polar solvents associated with a planarization of the excited-state geometry. This is particularly the case for the naphthalenic compound MC6 for which the fluorescence quantum yield is one order of magnitude larger in acetonitrile (almost $50 \%$ ) than in cyclohexane (5\%).[34] The value of $k_{n r}$ for MC4 is 5 to 10 fold larger than that for MC6 depending on the solvent. The redshift of absorption and emission spectra of dyes MC4 and MC6 as compared to M'4 and M'6, respectively, in DCM and other solvents, can originate from the occurrence of a more planar structure imposed by the tetralone unit.[34]

\section{Solid state photophysical properties}

We also investigated the emission properties of the boron difluoride complexes in the solid state (powder form) by measuring their emission spectra and their fluorescence quantum yields. All compounds were found to be emissive in the solid state (Table 2, Figure 2) with fluorescence quantum yields ranging from $2 \%$ to $24 \%$. The dyes emit mainly in the visible with the exception of 5 that reaches the NIR region of the spectrum.

The shape of spectra of the boron difluoride 2, 3, 7 and M1 (Figures 3a and 3b) is unsymmetrical revealing the occurrence of different chromophore populations in the powder samples while all other spectra displayed a structureless emission band that suggests that emission originated from a single population of complexes in the thin films (Figure 3).

It is interesting to note that boron difluoride complexes $\mathbf{4}, \mathbf{M C 4}$ and $\mathbf{5}$ display fluorescence with quantum yields higher than in DCM solution, which demonstrates that those dyes show aggregation enhanced emission (AIE). For $\mathbf{4}$ and MC4, the emission is red shifted by more than $100 \mathrm{~nm}$ with respect to the spectra recorded in DCM. The case of $\mathbf{5}$ is spectacular since no detectable emission was observed in DCM solution and aggregation-induced NIR emission $(742 \mathrm{~nm}$ ) is clearly observed albeit the fluorescence quantum yield remains low (2\%). For all other dyes, despite the occurrence of restricted intramolecular rotation in the solid, the fluorescence quantum yields are lower than in DCM solution, which indicated that aggregation-induced emission was not operative in these cases. 

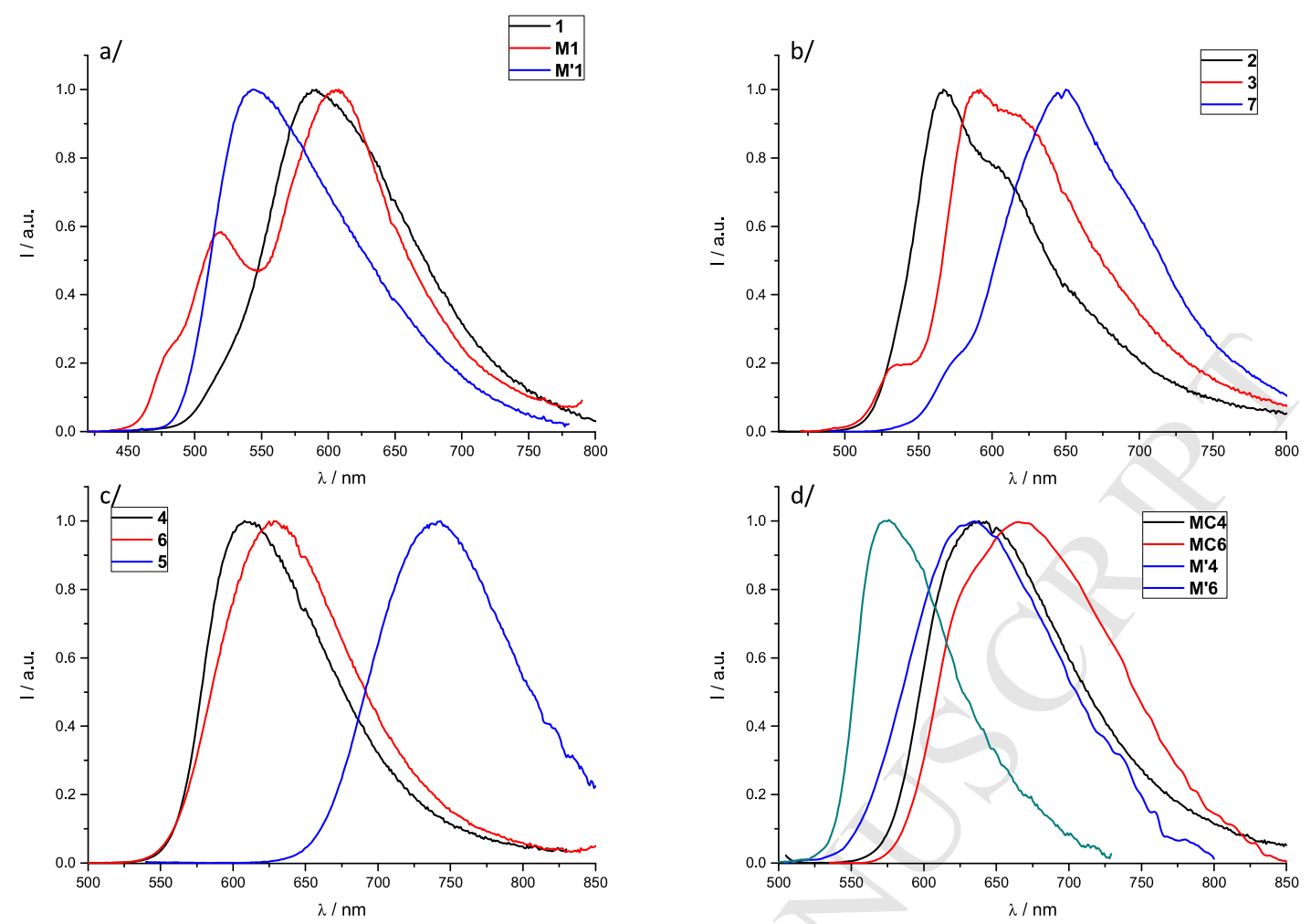

Figure 3. Normalized fluorescence spectra of powder of a/ 1 (-), M1 (-) and M'1 (-); b/ 2 (-), 3 (-) and 7 (-); c/ 4 (-), 6 (-) and 5 (-) and d/ MC4 (-), MC6 (-), M'4 (-) and M'1 (-).

Here, it has to be highlighted that the boron difluoride complexes 3 and $\mathbf{4}$, which present some of the highest fluorescence quantum yield values within the series reported here $(23 \%$ and $16 \%$, respectively), are not the ones that exhibit the more tightly packed dimers compared to compounds 6 and 7. It can be seen that 3 and 4 emit in the visible region of the spectrum at shorter wavelength $(<610 \mathrm{~nm})$. In contrast, the very tight packing of 6 and 7 in the crystal results in fluorescence emission at much longer wavelength $(>630 \mathrm{~nm})$ but with a weaker efficiency (fluorescence quantum yield $c a$. 7\%). These observations are in close agreement with the conclusions drawn by some of us on the fluorescence emission properties of a series of dipolar dyes, the boron difluoride complexes of chalcone, in the solid state.[48]

\section{Conclusion}

In this study, we report on the synthesis and characterization of the photophysical properties of novel boron difluoride complexes of hemicurcuminoid-related compounds containing a 
triple bond. Those dyes are emissive in solution and in the solid state. Within those new dyes, the compounds that emit through an efficient CT state show low fluorescence quantum yields and solvatochromic behavior. It can be observed that, increasing the donor strength, the fluorescence quantum yield highly decreases which is attributed to the formation of a photoinduced electron transfer state. In contrast, high fluorescence quantum yields reaching 70$80 \%$ can be obtained for the dyes lacking donor groups on the B side. Similarly to hemicurcuminoid previously reported,[34] those dyes are emissive in the solid state mostly, fluorescence emission being located in the visible and reaching quantum yields of $23 \%$ for $\mathbf{2}$. However, on the opposite of the previously reported hemicurcuminoid boron difluoride,[34] some of those dyes show aggregation induced emission effect. Those hemicurcuminoid-like dyes outperform boron difluoride of hydroxychalcone dyes in solution with much larger fluorescence quantum yields and brightness.[48] However, in the solid state, the performances of the latter (especially, their NIR emission) cannot be reached. These results provide important insights into the photophysics of the broad family of dipolar dyes based on the $\mathrm{BF}_{2}$ complexes of bidentate $\mathrm{O}^{\wedge} \mathrm{O}$ ligands containing a negatively-charged oxygen atom. This study is believed to serve as a strong basis for future works devoted to the development of high performance $\mathrm{BF}_{2}$-containing dyes for applications.

\section{Acknowledgements}

This work has been carried out in the framework of International Associated Laboratory "Functional nanostructures: morphology, nanoelectronics and ultrafast optics" (LIA NANOFUNC), France. ADA, E. K, E. C and JW. W. are supported by funding of the Ministry of Science, ICT \& Future Planning, Korea (2015001948, 2014M3A6B3063706). D. J. acknowledges both the European Research Council for the starting grant (Marches no. 278845) and the Région des Pays de la Loire for the LUMOMAT project. We thank the CCIPL (Centre de Calcul Intensif des Pays de la Loire) and the GENCI-CINES/IDRIS for the allocation of computing time. M.P.-V. thanks the ANR (project ANR-14-CE05-0035-02) for his postdoctoral grant. We also thank the Slovenian Research Agency for the financial support through grant P1-0179. X-Ray crystal structures of 3, 4, 6 and 7 have been deposited to CCDC and are referenced as followed CCDC 1515132, CCDC 1515133, CCDC 1515134 and CCDC 1515135, respectively.

\section{References}


[1] De Meulenaere E, Chen W-Q, Van Cleuvenbergen S, Zheng M-L, Psilodimitrakopoulos S, Paesen R, et al. Molecular engineering of chromophores for combined second-harmonic and two-photon fluorescence in cellular imaging. Chem Sci. 2012;3(4):984-95.

[2] Kim HM, Cho BR. Small-Molecule Two-Photon Probes for Bioimaging Applications. Chem Rev. 2015;115(11):5014-55.

[3] Wang Xiaochi CG, Cao Ruijun, Meng Lingjie. Structure and Properties of Near-Infrared Fluorescent Dyes and the Bioimaging Application. Prog Chem. 2015;27(7):794-805.

[4] Uoyama H, Goushi K, Shizu K, Nomura H, Adachi C. Highly efficient organic lightemitting diodes from delayed fluorescence. Nature. 2012;492(7428):234-8.

[5] Lin Z, Li C, Meng D, Li Y, Wang Z. Hybrid Corannulene-Perylene Dyes: Facile Synthesis and Optoelectronic Properties. Chem Asian J. 2016;11(19):2695-9.

[6] Méhes G, Pan C, Bencheikh F, Zhao L, Sugiyasu K, Takeuchi M, et al. Enhanced Electroluminescence from a Thiophene-Based Insulated Molecular Wire. ACS Macro Lett. 2016;5(7):781-5.

[7] Jiang W, Li Y, Wang Z. Tailor-Made Rylene Arrays for High Performance n-Channel Semiconductors. Acc Chem Res. 2014;47(10):3135-47.

[8] Huckaba AJ, Yella A, McNamara LE, Steen AE, Murphy JS, Carpenter CA, et al. Molecular Design Principles for Near-Infrared Absorbing and Emitting Indolizine Dyes. Chem Eur J. 2016;22(43):15536-42.

[9] Ulrich G, Ziessel R, Harriman A. The Chemistry of Fluorescent BODIPY Dyes: Versatility Unsurpassed. Angew Chem Int Ed. 2008;47(7):1184-201.

[10] Boens N, Verbelen B, Dehaen W. Postfunctionalization of the BODIPY Core: Synthesis and Spectroscopy. Eur J Org Chem. 2015;2015(30):6577-95.

[11] Kowada T, Maeda H, Kikuchi K. BODIPY-based probes for the fluorescence imaging of biomolecules in living cells. Chem Soc Rev. 2015;44(14):4953-72.

[12] Lu H, Mack J, Nyokong T, Kobayashi N, Shen Z. Optically active BODIPYs. Coord Chem Rev. 2016;318:1-15.

[13] Ge Y, O'Shea DF. Azadipyrromethenes: from traditional dye chemistry to leading edge applications. Chem Soc Rev. 2016;45(14):3846-64.

[14] Collado D, Vida Y, Najera F, Perez-Inestrosa E. PEGylated aza-BODIPY derivatives as NIR probes for cellular imaging. RSC Adv. 2014;4(5):2306-9.

[15] Fan G, Yang L, Chen Z. Water-soluble BODIPY and aza-BODIPY dyes: synthetic progress and applications. Front Chem Sci Eng. 2014;8(4):405-17.

[16] D’Aléo A, Fages F. Boron Complexes as Solid-State Fluorophores. Display Imaging. 2014;1(2):149-74.

[17] Zhao Z, Chen B, Geng J, Chang Z, Aparicio-Ixta L, Nie H, et al. Red Emissive Biocompatible Nanoparticles from Tetraphenylethene-Decorated BODIPY Luminogens for Two-Photon Excited Fluorescence Cellular Imaging and Mouse Brain Blood Vascular Visualization. Part Part Syst Charact. 2014;31(4):481-91.

[18] Gomez-Duran CFA, Hu R, Feng G, Li T, Bu F, Arseneault M, et al. Effect of AIE Substituents on the Fluorescence of Tetraphenylethene-Containing BODIPY Derivatives. ACS Appl Mater Interfaces. 2015;7(28):15168-76.

[19] Zhang G, Chen J, Payne SJ, Kooi SE, Demas JN, Fraser CL. Multi-Emissive Difluoroboron Dibenzoylmethane Polylactide Exhibiting Intense Fluorescence and OxygenSensitive Room-Temperature Phosphorescence. J Am Chem Soc. 2007;129(29):8942-3.

[20] Pfister A, Zhang G, Zareno J, Horwitz AF, Fraser CL. Boron Polylactide Nanoparticles Exhibiting Fluorescence and Phosphorescence in Aqueous Medium. ACS Nano. 2008;2(6):1252-8.

[21] Zhang G, Singer JP, Kooi SE, Evans RE, Thomas EL, Fraser CL. Reversible solid-state mechanochromic fluorescence from a boron lipid dye. J Mater Chem. 2011;21(23):8295-9. 
[22] Nguyen ND, Zhang G, Lu J, Sherman AE, Fraser CL. Alkyl chain length effects on solid-state difluoroboron $\beta$-diketonate mechanochromic luminescence. J Mater Chem. 2011;21(23):8409-15.

[23] Lanoë P-H, Mettra B, Liao YY, Calin N, D'Aléo A, Namikawa T, et al. Theoretical and Experimental Study on Boron $\beta$-Diketonate Complexes with Intense Two-Photon-Induced Fluorescence in Solution and in the Solid State. ChemPhysChem. 2016;17(14):2128-36.

[24] Poon C-T, Wu D, Yam VW-W. Boron(III)-Containing Donor-Acceptor Compound with Goldlike Reflective Behavior for Organic Resistive Memory Devices. Angew Chem Int Ed. 2016;55(11):3647-51.

[25] Domercq B, Grasso C, Maldonado J-L, Halik M, Barlow S, Marder SR, et al. ElectronTransport Properties and Use in Organic Light-Emitting Diodes of a Bis(dioxaborine)fluorene Derivative. J Phys Chem B. 2004;108(25):8647-51.

[26] Hales JM, Matichak J, Barlow S, Ohira S, Yesudas K, Brédas J-L, et al. Design of Polymethine Dyes with Large Third-Order Optical Nonlinearities and Loss Figures of Merit. Science. 2010;327(5972):1485-8.

[27] Karpenko IA, Niko Y, Yakubovskyi VP, Gerasov AO, Bonnet D, Kovtun YP, et al. Push-pull dioxaborine as fluorescent molecular rotor: far-red fluorogenic probe for ligandreceptor interactions. J Mater Chem C. 2016;4(14):3002-9.

[28] Ran C, Xu X, Raymond SB, Ferrara BJ, Neal K, Bacskai BJ, et al. Design, Synthesis, and Testing of Difluoroboron-Derivatized Curcumins as Near-Infrared Probes for in Vivo Detection of Amyloid- $\beta$ Deposits. J Am Chem Soc. 2009;131(42):15257-61.

[29] Zhang X, Tian Y, Li Z, Tian X, Sun H, Liu H, et al. Design and Synthesis of Curcumin Analogues for in Vivo Fluorescence Imaging and Inhibiting Copper-Induced Cross-Linking of Amyloid Beta Species in Alzheimer's Disease. J Am Chem Soc. 2013;135(44):16397-409.

[30] Felouat A, D'Aléo A, Fages F. Synthesis and Photophysical Properties of Difluoroboron Complexes of Curcuminoid Derivatives Bearing Different Terminal Aromatic Units and a meso-Aryl Ring. J Org Chem. 2013;78(9):4446-55.

[31] D'Aleo A, Felouat A, Heresanu V, Ranguis A, Chaudanson D, Karapetyan A, et al. Twophoton excited fluorescence of BF2 complexes of curcumin analogues: toward NIR-to-NIR fluorescent organic nanoparticles. J Mater Chem C. 2014;2(26):5208-15.

[32] Liu K, Chen J, Chojnacki J, Zhang S. $\mathrm{BF}_{3} \cdot \mathrm{OEt}_{2}$-promoted concise synthesis of difluoroboron-derivatized curcumins from aldehydes and 2,4-pentanedione. Tetrahedron Lett. 2013;54(16):2070-3.

[33] Bai G, Yu C, Cheng C, Hao E, Wei Y, Mu X, et al. Syntheses and photophysical properties of $\mathrm{BF}_{2}$ complexes of curcumin analogues. Org Biomol Chem. 2014;12(10):161826.

[34] Kim E, Felouat A, Zaborova E, Ribierre J-C, Wu JW, Senatore S, et al. Borondifluoride complexes of hemicurcuminoids as bio-inspired push-pull dyes for bioimaging. Org Biomol Chem. 2016;14:1311-24.

[35] Rivoal M, Zaborova E, Canard G, D'Aléo A, Fages F. Synthesis, electrochemical and photophysical studies of the borondifluoride complex of a meta-linked biscurcuminoid. New $\mathbf{J}$ Chem. 2016;40(2):1297-305.

[36] Štefane B. Selective Addition of Organolithium Reagents to $\mathrm{BF}_{2}$-Chelates of $\beta$ Ketoesters. Org Lett. 2010;12(13):2900-3.

[37] Parker CA. Photoluminescence of Solutions. Amsterdam: Elsevier Publishing, 1969.

[38] Lakowicz JR. Principles of Fluorescence Spectroscopy. 3rd ed. New-York (NY): Kluwer, 2006

[39] Crosby GA, Demas JN. Measurement of photoluminescence quantum yields. Review. J Phys Chem. 1971;75(8):991-1024. 
[40] Connelly NG, Geiger WE. Chemical Redox Agents for Organometallic Chemistry. Chem Rev. 1996;96(2):877-910.

[41] Frisch MJ, Trucks GW, Schlegel HB, Scuseria GE, Robb MA, Cheeseman JR, et al. Gaussian 09, Revision B.01. Gaussian 09, Revision B01. 2009.

[42] Adamo C, Barone V. Toward reliable density functional methods without adjustable parameters: The PBE0 model. J Chem Phys 1999,;110(13):6158-70.

[43] Ernzerhof M, Scuseria GE. Assessment of the Perdew-Burke-Ernzerhof ExchangeCorrelation Functional. J Chem Phys. 1999;110:5029-36.

[44] Tomasi J, Mennucci B, Cammi R. Quantum Mechanical Continuum Solvation Models. Chem Rev. 2005;105(8):2999-3094.

[45] Cossi M, Barone V. Time-dependent density functional theory for molecules in liquid solutions. J Chem Phys. 2001;115:4708-17.

[46] Improta R, Barone V, Scalmani G, Frisch MJ. A state-specific polarizable continuum model time dependent density functional theory method for excited state calculations in solution. J Chem Phys. 2006;125:054103.

[47] Reichardt C. Solvatochromic Dyes as Solvent Polarity Indicators. Chem Rev. 1994;94(8):2319-58.

[48] D'Aléo A, Gachet D, Heresanu V, Giorgi M, Fages F. Efficient NIR-Light Emission from Solid-State Complexes of Boron Difluoride with 2'-Hydroxychalcone Derivatives. Chem Eur J. 2012;18(40):12764-72.

[49] D’Aléo A, Heresanu V, Giorgi M, Le Guennic B, Jacquemin D, Fages F. NIR Emission in Borondifluoride Complexes of 2'-Hydroxychalcone Derivatives Containing an Acetonaphthone Ring. J Phys Chem C. 2014;118(22):11906-18.

[50] Kamada K, Namikawa T, Senatore S, Matthews C, Lenne P-F, Maury O, et al. Borondifluoride Curcuminoid Fluorophores with Enhanced Two-Photon Excited Fluorescence Emission and Versatile Living-Cell Imaging Properties. Chem Eur J. 2016;22(15):5219-32.

[51] Lippert E. Dipolmoment und elektronenstruktur von angeregten molekülen. Naturforsch. 1955;10a:541-5.

[52] Mataga EZ, Kaifu Y, Koizumi M. Solvent Effects upon Fluorescence Spectra and the Dipole-moments of Excited Molecules. Bull Chem Soc Jpn 1956;29:465-70.

[53] Lippert E. Spectroscopic determination of the dipole moment of aromatic compounds in the first excited singlet state. Z Elektrochem. 1957;61:962-75.

[54] Leroy S, Soujanya T, Fages F. Zinc(II)-operated intramolecular charge transfer fluorescence emission in pyrene-2,2'-bipyridine conjugated molecular rods. Tetrahedron Lett. 2001;42(9):1665-7.

[55] Leroy-Lhez S, Allain M, Oberle J, Fages F. Synthesis and zinc(II) complexation modulated fluorescence emission properties of two pyrene-oligo(phenylene vinylene)-2,2'bipyridine conjugated molecular rods. New J Chem. 2007;31(6):1013-21.

[56] Benniston AC, Grosshenny V, Harriman A, Ziessel R. New J Chem. 1997;21(21):405. 
Synthesis of new fluorophores based on hemicurcuminoid boron difluoride.

Photophysical study reveals strong emission of the dyes not containing charge transfer states.

Fluorescence properties of dyes in their condensed phase show aggregation induced emission. 